\title{
Enfermagem na terapia transfusional e hemovigilância: análise da conformidade em um hospital de ensino
}

\author{
Halana Batistel Barbosa ${ }^{1}$ Anair Lazzari Nicola²
}

\begin{abstract}
RESUMO
Objetivo: Analisar a conformidade da prática do enfermeiro na terapia transfusional, de acordo com a legislação vigente, e sua participação nas ações de hemovigilância. Metodologia: Pesquisa exploratória descritiva, realizada em um hospital de ensino do oeste do Paraná, envolvendo 24 enfermeiros que desenvolviam ações de hemoterapia. Utilizou-se um instrumento de coleta de dados para avaliar a prática hemoterápica dos enfermeiros. Resultados: Dos participantes, 58\% referem estar pouco informados sobre o assunto e $63 \%$ não orientam o paciente sobre os riscos da terapia. Um total de $63 \%$ rotula a amostra no posto de enfermagem longe do paciente, o que tende à indução do erro, considerando a demanda de trabalho e 0 aporte de recursos humanos nem sempre adequados. E 46\% não receberam treinamentos sobre o tema. Conclusão: $O$ desenvolvimento de programas de capacitação do enfermeiro sobre terapia transfusional pode ser uma estratégia para qualificar a assistência e atender a legislação.
\end{abstract}

Descritores: Segurança transfusional; Enfermagem; Hemovigilância

\section{Nursing on transfusion therapy and hemovigilance: analysis of compliance on a teaching hospital}

\begin{abstract}
Objective: To analyze the compliance of nursing practice in transfusion therapy, according to current legislation, and their participation in hemovigilance actions. Methodology: descriptive exploratory research held in a teaching hospital in western Paraná involving 24 nurses who developed actions hemotherapy. Was used a data collection instrument to assess nursing hemotherapy practice in accordance with the appropriate standards. Results: Of the participants, $58 \%$ they refer to be insufficiently informed about it and $63 \%$ did not guide the patient about the risks of therapy. A total of $63 \%$ label the sample at the nursing station away from the patient, it tends to induction of error considering the demand for labor and not always adequate supply of human resources. And $46 \%$ received no training on the subject. Conclusion: The development of training programs for nurses on transfusion therapy may be strategies for qualifying assistance and meet the legislation.
\end{abstract}

Descriptors: Transfusion safety; Nursing; Hemovigilance

\footnotetext{
1 Integrante do Grupo de Pesquisa em Administração dos Serviços de Saúde e de Enfermagem da Universidade Estadual do Oeste do Paraná (UNIOESTE), Cascavel, PR, Brasil

${ }^{2}$ Doutora em Enfermagem pela Universidade Estadual do Oeste do Paraná (UNIOESTE), Cascavel, PR, Brasil
} 


\section{Introdução}

A transfusão sanguínea, em algumas situações, pode representar a única maneira de melhorar rapidamente uma grave condição. Esta é considerada o tipo mais comum de transplante e é realizada em milhões de indivíduos todos os anos. ${ }^{1}$ A literatura demonstra que não existe transfusão isenta de riscos e que algumas delas podem trazer sérios prejuízos aos pacientes, inclusive fatais. É impossível eliminar totalmente as possibilidades de erro humano, porém, reduzir as chances de erro é um objetivo alcançável. Principalmente, quando se conta com uma equipe de médicos e enfermeiros que possuem níveis adequados de conhecimento relacionados ao tema. Sendo esta, a prerrogativa essencial para assegurar um sistema seguro de transfusão desde sua captação até o destino final - 0 paciente. ${ }^{2}$

A transfusão de hemocomponentes, enquanto terapia, ainda que indicada pelo contexto clínico e para que os resultados sejam satisfatórios, é imperativa a administração correta de acordo com as normas técnicas preconizadas. Visto que, as transfusões sanguíneas envolvem risco sanitário e podem ocasionar potenciais incidentes transfusionais. ${ }^{2,3}$

A legislação que regulamenta a prática hemoterápica no Brasil, RDC 57/2010 e Portaria 2.712/2013, determina as condições sanitárias para serviços que desenvolvem atividades relacionadas ao ciclo produtivo do sangue e procedimentos transfusionais, além de regulamentar as condições técnicas dos procedimentos hemoterápicos. Dessa forma, as instituições que realizam a prática hemoterápica devem seguir a legislação e possuir um sistema para a detecção, notificação e avaliação das complicações transfusionais. Incluindo procedimentos operacionais para tal finalidade, além do tratamento e prevenção das reações transfusionais. ${ }^{3,4}$

Partindo desse pressuposto, esta pesquisa poderá contribuir na avaliação da prática transfusional realizada pelo enfermeiro, bem como, as ações de hemovigilância por ele desenvolvidas. Com a finalidade de melhoria da segurança, especialmente, para os pacientes receptores e também para os profissionais da saúde, favorecendo assim, um atendimento de qualidade à população. Nesse sentido, objetiva-se analisar a conformidade da prática do enfermeiro na terapia transfusional de acordo com a legislação vigente e sua participação nas ações de hemovigilância.

\section{Metodologia}

Estudo exploratório descritivo, realizado em um hospital de ensino do oeste do Paraná, o qual possui 195 leitos e é referência regional em alta complexidade nas áreas de: gestação de alto risco, ortopedia/traumatologia, cirurgia vascular, neurologia/neurocirurgia e tratamento em portadores do Vírus da Imunodeficiência Humana (HIV).

Para fins do presente, consideraram-se população da pesquisa as unidades que mais realizam transfusão sanguínea neste nosocômio: unidade de Clínica Médica e Cirúrgica (F2), Pronto Socorro (PS), Centro Cirúrgico (CC) e Unidade de Terapia Intensiva adulto (UTI). O número total de enfermeiros correspondentes a estas unidades nos períodos estabelecidos era de 29, destes, 24 aceitaram participar da pesquisa. Sendo considerado critério de inclusão ser enfermeiro das referidas unidades e aceitar mediante consentimento livre e esclarecido participar da presente pesquisa, foi considerado como critério de exclusão apenas a recusa do profissional Os valores apresentados foram fornecidos pelo Serviço de Hemovigilância do hospital em questão, sendo o período definido em função da disponibilidade dos dados.

A pesquisa foi realizada mediante coleta de dados por meio da aplicação de um questionário previamente elaborado contendo apenas questões objetivas. O questionário foi aplicado no mês de dezembro de 2013, nos turnos matutino, vespertino e noturno aos enfermeiros das unidades mediante anuência através de termo de consentimento livre e esclarecido.

A análise dos dados foi permeada pela legislação vigente em hemoterapia, sendo destacados destas, informações concernentes ao conhecimento do enfermeiro frente à prática transfusional, às ações pré-transfusionais e às ações realizadas pelo enfermeiro durante a transfusão, não esgotando dessa forma, o uso da legislação para análise do trabalho em hemoterapia. Procedeu-se a análise por meio da estatística descritiva, com auxílio do Programa Microsoft Excel $2010^{\circledR}$ com posterior apresentação tabular dos resultados.

A presente pesquisa foi desenvolvida cumprindo os preceitos da Resolução 466/2012 da Comissão Nacional de Ética em Pesquisa, com a aprovação da instituição e do Comitê de Ética em Pesquisa da Universidade Estadual do Oeste do Paraná (UNIOESTE), sob protocolo número 461.232. 


\section{Resultados e discussão}

A população do presente estudo foi composta por quatro unidades hospitalares, baseada de acordo com a demanda de transfusões nelas realizadas. O setor do Pronto Socorro (PS) foi o que apresentou a maior taxa de transfusões realizadas, as demais unidades e suas respectivas transfusões estão descritas na Tabela 1.

Tabela 1 - Relação quantitativa das transfusões sanguíneas realizadas no Hospital em análise, no período de outubro de 2012 a setembro de 2013

\begin{tabular}{c|c|c}
\hline Unidades & $\mathbf{N}^{\circ}$ de transfusões & $\%$ \\
\hline F2 & 467 & 19 \\
\hline PS & 837 & 35 \\
\hline CC & 400 & 17 \\
\hline UTI & 717 & 30 \\
\hline Total & 2421 & 100 \\
\hline
\end{tabular}

FONTE: Dados do Serviço de Hemovigilância do Hospital em análise

Dos 24 participantes, 83\% eram do sexo feminino reafirmando assim, a tradição de que a profissão de enfermagem é majoritariamente composta por mulheres, $92 \%$ dos participantes possuíam pós-graduação latu sensu concluída. A Tabela 02 demonstra a descrição desta amostragem, onde se observa que o maior tempo de atuação em unidade hospitalar é entre sete a nove anos expressa por $46 \%$ dos participantes e que, $54 \%$ dos enfermeiros eram formados entre sete a dez anos.

Tabela 02 - Descrição da amostragem em função das variáveis: sexo, pós graduação latu sensu, tempo de atuação em unidade hospitalar e tempo de formação.

\begin{tabular}{|c|c|c|}
\hline & $\mathbf{N}$ & $\%$ \\
\hline \multicolumn{3}{|l|}{ Sexo } \\
\hline Masculino & 04 & 17 \\
\hline Feminino & 20 & 83 \\
\hline \multicolumn{3}{|c|}{ Pós Graduação latsu sensu } \\
\hline Em andamento & 02 & 08 \\
\hline Concluída & 22 & 92 \\
\hline \multicolumn{3}{|c|}{ Tempo de atuação em uniadade hospitalar } \\
\hline 01 a 03 anos & 04 & 17 \\
\hline 04 a 06 anos & 05 & 21 \\
\hline 07 a 09 anos & 11 & 46 \\
\hline$>10$ anos & 04 & 17 \\
\hline \multicolumn{3}{|l|}{ Tempo de formação } \\
\hline 01 a 03 anos & 01 & 04 \\
\hline 04 a 06 anos & 04 & 17 \\
\hline 07 a 09 anos & 13 & 54 \\
\hline$>10$ anos & 05 & 21 \\
\hline Não respondeu & 01 & 04 \\
\hline
\end{tabular}




\section{Considerações acerca do conhecimento em terapia transfusional}

Quando questionados se estavam informados sobre a terapia/prática transfusional, $04 \%$ respondeu estar mal informado, $58 \%$ responderam estar pouco informado, $33 \%$ se sentem informados e $04 \%$ se sente muito bem informado sobre a temática. Em relação à frequência na realização das transfusões, 33\% dos participantes referem realizar procedimentos transfusionais diariamente, $63 \%$ semanalmente e $04 \%$ mensalmente.

As atividades referentes ao ciclo produtivo do sangue devem ser realizadas por profissionais de saúde em número suficiente, habilitados e capacitados para a realização dessas atividades. Além do mais, as instituições de saúde que desenvolvem a prática hemoterápica devem garantir capacitação e constante atualização do profissional envolvido nos procedimentos, mantendo os respectivos registros, bem como cumprir as determinações legais. ${ }^{3,4}$

Nesse sentido, considerando a alta frequência com que são realizados procedimentos transfusionais na instituição em análise, os profissionais que atuam diretamente nessa prática necessitam deter o conhecimento necessário tanto para prestar assistência de qualidade quanto para prover sua própria segurança no ambiente de trabalho. ${ }^{5}$ Dessa forma, é pertinente a inferência de que, há uma necessidade de elaboração e execução de propostas de educação permanente vinculadas ao desenvolvimento e qualificação das ações necessárias para a prática hemoterápica.

Os profissionais foram questionados sobre se recebiam treinamentos para a prática transfusional, $46 \%$ responderam que não receberam treinamentos sobre essa prática. Já, $63 \%$ enfermeiros responderam que não receberam treinamentos relacionados à atuação em casos de reação transfusional, conforme Tabela 03.

Tabela 03 - Frequência relatada sobre o recebimento de treinamentos sobre prática hemoterápica e hemovigilância pela instituição.

\begin{tabular}{c|c|c|c|c|c|c}
\hline \multirow{2}{*}{$\begin{array}{c}\text { Treinamento } \\
\text { sobre }\end{array}$} & $\mathrm{n}$ & $\%$ & $\mathrm{n}$ & \multicolumn{2}{c}{ Às Vezes } & $\%$ \\
\cline { 2 - 6 } & 04 & 17 & 09 & 38 & 11 & $\mathrm{n}$ \\
\hline $\begin{array}{c}\text { Prática } \\
\text { Transfusional }\end{array}$ & 04 & & & & & 46 \\
\hline $\begin{array}{c}\text { Identificar e } \\
\text { proceder em } \\
\text { casos de reação } \\
\text { transfusional }\end{array}$ & 04 & 17 & 05 & 21 & 15 & 63 \\
\hline
\end{tabular}

Os enfermeiros foram questionados sobre se tinham segurança quanto às condutas a serem adotadas em caso de reação transfusional. Do total dos participantes $33 \%$ dos profissionais responderam ter segurança nas condutas a serem tomadas frente a uma reação, $46 \%$ afirmaram que as vezes tinham segurança e $21 \%$ que não sentiam segurança na tomada de decisão frente a uma reação transfusional. Diante disso, cabe destacar que há a possibilidade da ocorrência frequente de condutas inadequadas frente as reações transfusionais, devido ao número reduzido de profissionais que afirmaram ter segurança nessas situações. A conduta inadequada frente a uma reação transfusional pode comprometer o progresso clínico do paciente. Além disso, podem não contribuir com o ciclo produtivo do sangue impedindo que, ações de correção e melhoria sejam estabelecidas pelos setores competentes visto que, não são encaminhados para estes, as dúvidas relacionadas ao procedimento transfusional. ${ }^{6}$

Em estudo realizado com objetivo de evidenciar o conhecimento da equipe de enfermagem em relação aos cuidados aos pacientes em terapia transfusional, evidenciou-se a necessidade da equipe de enfermagem de buscar maiores conhecimentos sobre a sua prática. Tendo em vista que, os pacientes receptores quase que exclusivamente, se encontravam aos cuidados da equipe de enfermagem. ${ }^{5}$

Os resultados obtidos na presente pesquisa corroboram com estudos realizados, uma vez que a maioria dos profissionais respondeu não receber nenhum treinamento relacionado à prática transfusional, bem como, sobre identificar e proceder em casos de reação transfusional. Portanto, é evidente a necessidade de treinamentos em serviço que visem adequar a prática profissional para atender ao disposto na legislação vigente, uma vez que 
grande objetivo é produzir conhecimento específico e atualizado, sendo necessário rever o processo de formação e os programas de treinamento desses profissionais [...]. $]^{6: s / p}$

A terapia transfusional é complexa e exige conhecimentos específicos em todo seu processo e, para tanto, necessita de profissionais capacitados para que os procedimentos hemoterápicos sejam realizados com o máximo de segurança. Considerando o disposto na Resolução 306/2006 do Conselho Federal de Enfermagem que, fixa como competências e atribuições do enfermeiro na área de hemoterapia planejar, executar, coordenar, supervisionar e avaliar os procedimentos de hemoterapia nas unidades de saúde. ${ }^{7}$

As necessidades educativas partem da realidade do trabalho devendo unir preceitos teóricos - uma vez que a formação técnica ou acadêmica não supre integralmente as necessidades da vida profissional - com a experiência dos trabalhadores. Isso, com a finalidade de fortalecer uma prática crítica utilizando o conhecimento acumulado. ${ }^{5}$

\section{Ações de enfermagem na fase pré-transfusional}

Quando questionados sobre em qual momento os profissionais de enfermagem realizavam a rotulagem das amostras a serem enviadas para análise para posterior transfusão, um total de $63 \%$ dos enfermeiros afirmou que a rotulagem era feita no posto de enfermagem da unidade, $33 \%$ realizavam a rotulagem na cabeceira do leito logo após a coleta do material e $04 \%$ referiu realizar a rotulagem tanto no posto quanto a beira leito.

Sabe-se que todas as amostras devem ser rotuladas no momento da coleta. A identificação deve ser completa, com nome completo do receptor sem abreviaturas, seu número de identificação, identificação de quem realizou a coleta e data da mesma, sendo também, recomendável a identificação por código de barras ou etiqueta impressa. ${ }^{4}$

Nesse sentido, pode-se afirmar que, cerca de $63 \%$ da população da pesquisa não segue o preconizado pela legislação e que tal prática tende a indução do erro. Isso se deve ao fato de que, considerando a demanda de trabalho e 0 aporte de recursos humanos nem sempre adequados, há a possibilidade de esquecimento do nome do paciente ou até mesmo de troca de pacientes. ${ }^{2-4}$

Os participantes da pesquisa foram questionados sobre a confirmação da identificação do paciente com a identificação da bolsa a ser transfundida. Demonstrando que, 100\% dos participantes responderam que realizam essa comparação sendo que desse total $96 \%$ comparam os nomes antes do procedimento e $04 \%$ realiza antes e durante o procedimento.

De acordo com a legislação vigente, o receptor deve ser identificado imediatamente antes da transfusão através da informação de seu nome completo pelo mesmo ou por seu acompanhante. Caso haja qualquer discrepância entre a identificação do receptor e a constante da bolsa, a transfusão deverá ser suspensa até o esclarecimento do fato. A finalidade da correta identificação do paciente é reduzir a ocorrência de incidentes, assim, o processo de identificação deve assegurar que o cuidado seja prestado à pessoa para a qual se destina. Dessa forma, o paciente deve estar identificado corretamente, o que tende a reduzir a possibilidade de erro na identificação do receptor na hipótese de este não se encontrar consciente e orientado. ${ }^{8}$

Quando questionados sobre o conhecimento referente ao sistema $\mathrm{ABO}-\mathrm{Rh}, 50 \%$ responderam que conheciam bem 0 sistema sanguíneo ABO-Rh e 50\% responderam não conhecer bem tal sistema.

Os participantes da presente pesquisa, foram questionados sobre qual o tipo sanguíneo é considerado o doador e o receptor universal, conhecimento considerado básico na realização de terapia transfusional. Dessa forma, $88 \%$ responderam que o tipo sanguíneo 0 negativo é o doador universal e 13\% dos enfermeiros responderam ser o tipo 0 positivo. Quanto ao tipo sanguíneo considerado receptor universal $79 \%$ responderam ser o tipo AB positivo, 17\% referem ser o tipo 0 positivo e $04 \%$ diz ser o tipo 0 negativo totalizando, portanto, $21 \%$ dos participantes que responderam inadequadamente a esta questão.

Entretanto, considerando a realidade institucional de que o maior número de transfusões foi realizada no Pronto Socorro, local onde são atendidos pacientes em graves condições, cabe destacar que na hipótese de transfusão de urgência ou emergência, a liberação de sangue total ou concentrado de hemácias, antes do término dos testes prétransfusionais, poderá ser feita, desde que o quadro clínico do paciente justifique a emergência. Nos casos de transfusão na modalidade de emergência, em que não houver tempo para tipagem do sangue do receptor, é recomendável o uso de hemácias $\mathrm{O}$ Rh negativo, entretanto, caso não haja esse tipo de sangue em estoque suficiente no serviço de 
hemoterapia, poderá ser usado O Rh positivo, sobretudo em pacientes do sexo masculino ou em pacientes de qualquer sexo com mais de 45 anos de idade. ${ }^{3,4}$

Quando questionados sobre se realizavam orientações sobre os benefícios da transfusão $13 \%$ dos participantes responderam positivamente. Quanto às orientações sobre os riscos da terapia transfusional, $04 \%$ responderam realizar essa orientação enquanto $63 \%$ referiram não realizar nenhuma orientação sobre os riscos dessa terapia. No que tange à informação sobre os sinais e sintomas que podem indicar a presença de uma reação transfusional, $17 \%$ dos enfermeiros responderam realizar essa orientação, de acordo com a Tabela 04.

Tabela 04 - Frequência relatada de orientações recebidas sobre riscos, benefícios e sinais e sintomas relacionados à transfusão sanguínea.

\begin{tabular}{c|c|c|c|c|c|c}
\hline \multirow{2}{*}{$\begin{array}{c}\text { Orientação } \\
\text { sobre }\end{array}$} & \multicolumn{2}{|c|}{ Sim } & \multicolumn{2}{c|}{ Às Vezes } & \multicolumn{2}{c}{ Não } \\
\cline { 2 - 7 } & $\mathrm{n}$ & $\%$ & $\mathrm{n}$ & $\%$ & $\mathrm{n}$ & $\%$ \\
\hline Benefícios & 03 & 13 & 14 & 58 & 01 & 04 \\
\hline Riscos & 01 & 04 & 08 & 33 & 15 & 63 \\
\hline $\begin{array}{c}\text { Sinais e } \\
\text { Sintomas }\end{array}$ & 04 & 17 & 10 & 42 & 10 & 42 \\
\hline
\end{tabular}

Todas as fases e riscos que envolvem 0 ato transfusional devem ser informados aos pacientes ou familiares pelos profissionais de saúde antes que se inicie o procedimento transfusional. ${ }^{3,4-6}$ Os resultados apontam que algumas vezes os pacientes são orientados quanto aos benefícios, mas, não quanto aos riscos. De um modo geral, a terapia transfusional demanda conhecimento das técnicas de aplicação, riscos e intervenção de forma efetiva em possíveis complicações. ${ }^{5}$

Ações de enfermagem durante a transfusão

No que diz respeito ao acompanhamento e monitoramento do procedimento transfusional em todo seu transcurso, $58 \%$ responderam acompanhar e monitorar o paciente, enquanto $33 \%$ responderam que 0 acompanhamento era realizado às vezes e $08 \%$ não acompanhavam a transfusão até o fim. Do total de participantes $33 \%$ afirmaram que o paciente era periodicamente monitorado/acompanhado pelo profissional que a instalou durante os 10 primeiros minutos à beira do leito, enquanto que $42 \%$ o faziam às vezes e $25 \%$ não relataram esse acompanhamento.

A transfusão deve ser monitorada durante todo seu transcurso, devendo a mesma ser acompanhada pelo profissional que a instalou durante os 10 primeiros minutos à beira do leito. $O$ enfermeiro possui como função acompanhar $e$ supervisionar as atividades realizadas pelos técnicos de enfermagem e atenção especial nos primeiros minutos do procedimento transfusional., ${ }^{3,4}$ Dessa forma, assistir de maneira integral o doador, o receptor e seus familiares, tendo como base o Código de Ética dos profissionais de enfermagem e as normas vigentes também são competências e atribuições do enfermeiro. ${ }^{7}$

Recomenda-se iniciar a infusão de forma lenta, permanecendo junto ao paciente o profissional responsável pelo procedimento transfusional. Objetivando a avaliação de possíveis alterações nos dados vitais, uma vez que, é comum a ocorrência de reações transfusionais no início da infusão e, a observação permite uma pronta intervenção caso a reação ocorra. ${ }^{5}$ Nesse sentido, compete ao enfermeiro além da execução, a supervisão da administração e a monitorização da infusão de hemocomponentes e hemoderivados, atuando nos casos de reações adversas. ${ }^{7}$

Quanto à identificação dos sinais e sintomas de reações adversas relacionadas ao uso de hemocomponentes durante e posterior ao processo transfusional, a maioria afirmou que às vezes são facilmente identificados durante a transfusão. Entretanto, esse quadro se intensifica quando a reação ocorre posteriormente à transfusão, conforme Tabela 05. 
Tabela 05 - Frequência relatada sobre a identificação de sinais e sintomas indicativos de reação transfusional durante e após o procedimento da tranfusão sanguínea.

\begin{tabular}{c|c|c|c|c|c|c}
\hline $\begin{array}{c}\text { Identificação } \\
\text { de } \begin{array}{c}\text { sinais } \\
\text { sintomas }\end{array}\end{array}$ & \multicolumn{2}{|c|}{ Sim } & \multicolumn{2}{c|}{ Às Vezes } & \multicolumn{2}{c}{ Não } \\
\cline { 2 - 7 } & $\mathrm{n}$ & $\%$ & $\mathrm{n}$ & $\%$ & $\mathrm{n}$ & $\%$ \\
\hline $\begin{array}{c}\text { Durante } \\
\text { procedimento }\end{array}$ & 09 & 38 & 12 & 50 & 03 & 13 \\
\hline Pós-transfusional & 02 & 08 & 16 & 67 & 06 & 25 \\
\hline
\end{tabular}

Tanto no reconhecimento dos sinais e sintomas durante a terapia quanto posterioramesma, $50 \%$ e $67 \%$, respectivamente, responderam às vezes. Dessa forma, nem sempre o evento adverso relacionado ao sangue e seus componentes são identificados e notificados como necessário ${ }^{3,4}$

Os enfermeiros foram questionados sobre o retorno da informação caso uma reação seja confirmada e notificada, $25 \%$ responderam que tomam conhecimento se uma reação é confirmada ou não, $17 \%$ responderam que às vezes tem acesso a essa informação e, $58 \%$ responderam que essa informação não chega até eles depois de concluídas as investigações. Isso nos remete à inferência de que não há retorno das investigações realizadas para aquele profissional que muitas vezes é o responsável pela identificação da reação transfusional.

O enfermeiro participa das ações de hemovigilância desde o momento do recebimento do hemocomponente na unidade. Deve realizar adequada identificação e inspeção, prestando assistência e orientação ao paciente durante o procedimento até o momento pós transfusional no qual ainda há a possibilidade de desenvolvimento de reação relacionada ao uso do hemocomponente.

$\mathrm{Na}$ ocorrência de incidente transfusional, o enfermeiro ao tomar decisões como a que se refere à devolução do componente ao serviço de hemoterapia está prestando assistência e ao mesmo tempo integrando uma ação de hemovigilância. 0 mesmo ocorre quando este profissional é devidamente capacitado a identificar os sinais e sintomas de um incidente transfusional e intervir prontamente iniciando o processo de notificação. Dessa forma, contribui para que a instituição tenha acesso a dados mais fidedignos e para que haja redução dos níveis de subnotificação dos eventos relacionados ao sangue e seus componentes.

\section{Considerações finais}

O estudo evidencia a importância do enfermeiro na prática transfusional, porquanto, necessita acompanhar a legislação vigente bem como, as atualizações referentes ao conhecimento específico dessa prática, visto que, a transfusão de hemocomponentes e hemoderivados consiste em um processo complexo não isento de riscos.

Os resultados apontam que, os enfermeiros se sentem pouco informados no que tange à prática hemoterápica e que nem sempre procedem com segurança frente a uma reação transfusional. Assim, é possível relacionar esses dados com a baixa realização de treinamentos tanto sobre a prática transfusional quanto sobre como identificar e proceder quando da ocorrência de reação transfusional.

Nesse sentido, há que se criar alternativas de capacitação permanente, pois o treinamento gera maior eficiência no trabalho, à medida que fornece ao profissional os conhecimentos de que precisa para fazer suas atividades. Tudo isso se torna fundamental para as ações de enfermagem, na terapia transfusional.

Ao avaliar a conformidade das práticas do enfermeiro, no que tange à terapia transfusional, bem como a participação nas ações de hemovigilância, permitiu o levantamento de como esses profissionais estão trabalhando com essa temática e se suas ações contribuem para a segurança do paciente. Nesse sentido, a pesquisa possibilitou a identificação de lacunas relacionadas à atuação do enfermeiro e algumas delas tendem a contribuir para subnotificação de incidentes transfusionais. A prática hemoterápica requer cada vez mais profissionais qualificados, garantindo dessa forma, qualidade e segurança no processo transfusional, para tanto, investimentos em capacitação e permanente atualização profissional são necessários para qualificar a assistência. 


\section{Referências bibliográficas}

1. Ministério da Saúde (BR).Manual técnico de hemovigilância. Brasília: Ministério da Saúde; Agência Nacional de Vigilância Sanitária - Anvisa; 2004.

2. Ministério da Saúde (BR). Hemovigilância: Manual técnico para investigação das reações transfusionais imediatas e tardias não infecciosas. Brasília: Ministério da Saúde; Agência Nacional de Vigilância Sanitária - Anvisa; 2007.

3. ANVISA. Resolução RDC n 57, de 16 de dezembro de 2010. Determina o Regulamento Sanitário para Serviços que desenvolvem atividades relacionadas ao ciclo produtivo do sangue humano e componentes e procedimentos transfusionais. Diário Oficial da União, Poder Executivo, 17 dez. 2010.

4. BRASIL. Portaria $n^{0}$ 2.712, de 12 de novembro de 2013. Redefine o Regulamento Técnico de Procedimentos Hemoterápicos. Diário Oficial da União n² 221, 13 nov. 2013. Seção 1, p. 106.

5. Silva LAA da, Somavilla MB. Conhecimentos da equipe de enfermagem sobre terapia transfusional. Cogitare enferm. 2010;15(2):327-33.

6. Silva KFN, Soares S, Iwamoto HH. A prática transfusional e a formação dos profissionais de saúde. Rev. Bras. Hematol. Hemoter. 2009.

7. Conselho Federal de Enfermagem. Resolução COFEN 306/2006. Normatiza a atuação do Enfermeiro em Hemoterapia.

8. Ministério da Saúde (BR). Protocolo de Identificação do Paciente. Brasília: Ministério da Saúde; Agência Nacional de Vigilância Sanitária - Anvisa; Fiocruz. Protocolo Integrante do Programa Nacional de Segurança do Paciente.

\section{Halana Batistel Barbosa}

Endereço para correspondência -

E-mail: halanabarbosa@hotmail.com

Lattes: http://buscatextual.cnpq.br/buscatextual/visualizacv.do?id=K4204263A5

Anair Lazzari Nicola - anairln@yahoo.com.br

Recebido em 03 de junho de 2014.

Publicado em 09 de outubro de 2014. 